\title{
DANÇA E DESCONSTRUÇÃO: OLHANDO PARA A OBRA DE PINA BAUSCH, WILLIAM FORSYTHE E MEG STUART
}

\author{
Cláudio Marcelo Carneiro Leão Lacerda \\ Universidade Federal de Pernambuco
}

\section{Resumo}

Este texto objetiva olhar para os coreógrafos contemporâneos Pina Bausch, William Forsythe e Meg Stuart e investigar o que faz com que suas obras sejam tão desestabilizadoras e provocadoras. Essa investigação foi feita pelo viés da teoria da desconstrução de Jacques Derrida e conceitos correlatos de outros autores, partindo de suas questões filosóficas para poder relacioná-las com os procedimentos criativos, propostas cênicas e abordagens de corpo dos referidos coreógrafos.

Palavras-chave: dança; corpo; coreografia; desconstrução.

\section{Abstract}

This text aims to look at contemporary coreographers Pina Bausch, William Forsythe and Meg Stuart and to investigate what makes their works so destabilizing and provocative. This investigation was done from the point of view of the theory of deconstruction of Jacques Derrida and correlate concepts by other authors, departing from his philosophical questions in order to relate them to the creative procedures, scenic proposals e approaches to the body of the mentioned choreographers.

Keywords: dance; body; choreography; deconstruction.

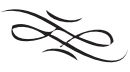

O principal motor da pesquisa ${ }^{1}$ que originou este texto foi investigar o que faz

$\infty<\infty<\infty<\infty<\infty<\infty<\infty<\infty<\infty<\infty<\infty<\infty<\infty<$

1 "Dança e Desconstrução", desenvolvida durante os anos acadêmicos de 2010 a 2013 na área de Dança, dentro do Departamento de Teoria da Arte e Expressão Artística da UFPE, na linha de pesquisa Teoria das 
com que as obras dos coreógrafos Pina Bausch, William Forsythe e Meg Stuart sejam tão desestabilizadoras e provocadoras. Realizamos tal investigação pelo viés da teoria da desconstrução, partindo de suas questões filosóficas para poder relacioná-las com os procedimentos criativos, propostas cênicas e abordagem de corpo dos referidos coreógrafos.

\section{A teoria da desconstrução e correlações}

As ferramentas conceituais concebidas por Jacques Derrida formam um dos mais importantes arcabouços teóricos da contemporaneidade. Ele preocupou-se em dissolver polaridades que têm constituído o pensamento e a filosofia ocidentais. Critica o Estruturalismo e o privilégio que este concede à linguagem para ser um explicador universal dos eventos do mundo, tendo como foco a importância altamente desproporcional conferida à forma em detrimento da força, ou melhor, por separar a forma da força.

Derrida propõe uma desconstrução da estrutura: "A estrutura, então, pode ser metodicamente ameaçada a fim de que possa ser compreendida mais claramente e revelar não apenas seus suportes mas também aquele lugar secreto no qual não é nem construção nem ruína mas labilidade" (DERRIDA, 2008: 5). A desconstrução surge como uma economia que escape ao sistema de oposições metafísicas: duração-espaço, qualidade-quantidade, força-forma, profundidade de significação-superfície das figuras. Nela, as diferenças examinadas seriam, simultaneamente, de sítio e de força. Para quebrar essa estrutura de oposições, proceder-se-ia através de um certo arranjo estratégico que usa as forças do próprio campo para virar seus estratagemas contra ele, produzindo uma força de deslocamento, que se espalha através do sistema inteiro, fissurando-o em toda direção e delimitando-o completamente (ibid.: 22). Derrida explica que essa ideia de desconstruir, de descentrar, de pensar a estruturalidade da estrutura, não surgiu de um único evento, uma única doutrina ou um único autor; ela é parte da totalidade de nossa era.

O espaço de tensão entre polaridades - forma-força, natureza-cultura, presença-representação, significante-significado, dentro-fora, imagem-realidade, corpo-alma - é um espaço que precisa ser habitado, um espaço de adiamento, de labilidade, de desestabilização, de devir, que não é valorizado pela filosofia e pela cultura ocidentais, justamente porque estas têm se baseado nessas polaridades para se produzir (2006: 66).

Um elemento importante para habitar esse espaço é o conceito de rastro. Derrida nega que haja uma presença absoluta, "uma lacuna intransponível existe entre ter um pensamento e registrá-lo e entre experienciar um sentimento e sabê-lo" (SCHROEDER, 2005: 281). Então, o que percebemos é o rastro, o próprio significante, o que é acessível da realidade. "A desconstrução da presença passa pela da consciência, logo, pela noção

Artes Plásticas e Cênicas do Grupo de Pesquisa Arte, Cultura e Memória. 
irredutível do rastro" (DERRIDA, 2006: 86). O conceito de arqui-rastro arranca o conceito de rastro ao esquema clássico que faria derivar de uma presença ou de um não rastro originário.

O rastro é verdadeiramente a origem absoluta de sentido em geral. O que vem afirmar, mais uma vez, que não há origem absoluta do sentido em geral. O rastro é a diferência que abre o aparecer e a significação. Articulando o vivo sobre o não-vivo em geral, origem de toda repetição, origem da idealidade, ele não é mais ideal que real, não mais inteligível que sensível, não mais uma significação transparente que uma energia opaca e nenhum conceito da metafísica pode descrevê-lo. (ibid.: 80)

Desfaz, portanto, a ideia de uma origem, ideia fundamental para uma onto-teologia. "Só o infinito positivo pode suspender o rastro, sublimá-lo. [...] As teologias infinitistas são sempre logocentrismos, quer sejam ou não criacionismos.” (ibid.: 87)

Desfazendo a ideia de origem, desfaz-se a ideia de passado absoluto e dissolve-se a ideia de passado, presente e futuro, pois o tempo é considerado uma passividade fundamental (ibid.: 82). Derrida diz que os filósofos frequentemente se enganam porque eles tomam o presente como anterior à rede encoberta que o faz possível (SCHROEDER, 2005: 285).

Espaçamento é outra ferramenta conceitual para habitar este espaço entre polaridades. Relaciona-se a pausa, branco, pontuação, intervalo em geral etc. São espaços de devir, de formação da significação.

O espaçamento [...] é sempre o não-percebido, o não-presente e o não-consciente. (ibid.: 83)

[...] o espaçamento como escritura é o vir-a-ser ausente e o vir-a-ser inconsciente do sujeito. Pelo movimento de sua deriva, a emancipação do sujeito retro-constitui o desejo da presença. [...] E a ausência original do sujeito da escritura é também a da coisa ou do referente. (ibid.: 84)

O conceito de diferência [differance] está baseado em uma "proliferação interminável de contrastes que multiplicam significações” (SCHROEDER, 2005: 284). A diferência age numa dimensão temporal e numa dimensão espacial. Na primeira, a significação é adiada até que o próximo elemento na série emirja (entretanto, a série nunca termina); na segunda, produz novas possibilidades de significação, contrastando termos uns com os outros (ibid.). A diferência dissolve as polaridades, pois não é nem uma origem nem um resultado, é tanto ativa quanto passiva, tanto produto quanto produção; também quebra o fundamento cartesiano principal, a separação corpo/mente, pois descreve o 
funcionamento dos processos mental e físico. Quando se dá a compreensão das implicações desse processo de diferência, muitas das distinções e polaridades fundadoras da filosofia e da linguística implodem.

A metafísica da presença, o logocentrismo, as ideias de estrutura, origem, passado absoluto, verdade, significado transcendental, todos eles, para funcionar, exigem um centro, uma presença central. O grande golpe desconstrutivista proposto por Derrida é a noção de que este centro não existe, de que o centro de cada estrutura é faltante.

A estrutura - ou antes, a estruturalidade da estrutura - apesar de ter estado sempre funcionando, tem sempre sido neutralizada ou reduzida, e isto por um processo de dar-lhe um centro ou de referir-lhe a um ponto de presença, uma origem fixa. A função deste centro foi não apenas orientar, equilibrar e organizar a estrutura - não se pode de fato conceber uma estrutura sem organização - mas, acima de tudo, certificar que o princípio organizador da estrutura limitaria o que poderíamos chamar de jogo da estrutura. Orientando e organizando a coerência do sistema, o centro de uma estrutura permite o jogo de seus elementos dentro da forma total. E até hoje a noção de uma estrutura da qual falta um centro representa o próprio impensável. (DERRIDA, 2008: 352)

Barthes afirmou que "descrever sistemas significantes postulando um significado último é tomar partido contra a própria natureza do sentido" (apud PERRONE-MOISÉS, 2005: 98). A noção de centro faltante ataca de frente o significado último.

Entretanto, para compensar esse centro faltante, esse não lugar [nonlocus], a estrutura terá que se valer da violência de uma verdade para se impor. Então, vai receber, sucessiva e regularmente, diferentes formas e nomes, em uma série de substituições de centro para centro. A história da metafísica, como a história do Ocidente, é a história
dessas metáforas e metonímias. Sua matriz - se me perdoarem por
demonstrar tão pouco e por ser tão elíptico a fim de chegar mais ra-
pidamente ao meu tema principal - é a determinação do Ser como
presença em todos os sentidos desta palavra. Poderia ser mostrado
que todos os nomes relacionados a fundamentos, a princípios, ou
ao centro têm sempre designado uma presença invariável - eidos,
arché, telos, energeia, ousia (essência, existência, substância, sujeito),
aletheia, transcendentalidade, consciência, Deus, homem, e daí pra
frente. (DERRIDA, 2008: 353 )

Fizemos uma ligação desses conceitos derridianos com as ideias de Homi Bhabha (1998) de "momento de trânsito", "sensação de desorientação", "emergência dos interstí- 
cios", "temporalidade intervalar", "entre-lugar", as quais, entre outras, evocam este lugar do entre, das lacunas, dos vãos, lugares onde novas significações surgem e se transformam. É nesses espaços que as criações desses três coreógrafos transitam. São trabalhos fronteiriços porque habitam essa tensão entre polaridades, esse entre-lugar.

O trabalho fronteiriço da cultura exige um encontro com "o novo" que não seja parte do continuum de passado e presente. Ele cria uma ideia do novo como ato insurgente de tradução cultural. Essa arte não apenas retoma o passado como causa social ou precedente estético; ela renova o passado refigurando-o como um "entre-lugar" contingente, que inova e interrompe a atuação do presente. $\mathrm{O}$ "passado-presente" torna-se parte da necessidade, e não da nostalgia, de viver. (BHABHA, 1998: 27)

Derrida (2006: 88) comenta sobre os "significantes acústicos", que equivalem a um conceito linearista de tempo, unidimensional, que corresponde ao conceito de signo que permanece inserido na história da ontologia clássica, a relação biunívoca entre face significante e face significada. Ciane Fernandes (2007) relaciona três maneiras nas quais se lida com o tempo na produção de significações:

a) o tempo linear, que liga passado-presente-futuro, numa configuração teleológica, o futuro como um alvo a ser conseguido, através de uma progressão;

b) o tempo circular, que evoca tradições por meio da repetição, revivendo e reproduzindo eventos, pensamentos, mitos; um tempo que foca no passado;

c) o tempo tridimensional, representado na figura do anel (ou fita) de Moebius, onde polaridades se confundem, o dentro converte-se em fora e vice-versa e, consequentemente, onde relações biunívocas se desestruturam: o passado torna-se presente, que torna-se futuro, que está adjacente/sobreposto a passado, onde força se encadeia junto a forma.

O anel de Moebius é o próprio espaço entre polaridades, onde as significações se pulverizam, não são estanques e são dinâmicas. Fernandes o utiliza para falar sobre o legado de Rudolf Laban e para pensar o procedimento coreográfico de Bausch. Aqui afirmamos que os trabalhos de Bausch, Forsythe e Stuart habitam essa relação do anel de Moebius. "A identidade a si do significado se esquiva e se desloca incessantemente" (DERRIDA, 2006: 60). 


\section{Sobre o medium da dança}

Para que possamos fazer a ligação entre a teoria da desconstrução e a obra dos referidos coreógrafos, teceremos, primeiramente, algumas considerações sobre o medium da dança. Este é formado pelas interrelações, ou nexo, entre os componentes da dança, segundo Adshead (1988) e Preston-Dunlop (1998), Movimento, Dançarino(a), Espaço/ Ambiente Visual e Elementos Sonoros.

São as relações entre os componentes que formam a estrutura, daí o movimento e outros elementos de natureza visual e sonora serem manipulados e colocados juntos em maneiras particulares para criar uma forma. Especificamente, as relações são criadas pelo movimento no tempo e espaço em associação com materiais visuais e sonoros. (ADSHEAD, 1988: 41)

O nexo é a rede invisível de conexões que mantém a obra una. Ele representa incontáveis decisões artísticas que nascem da visão de mundo em geral do artista e sua visão do lugar da dança dentro dele. (PRESTON-DUNLOP, 1998: 04)

É importante considerar a natureza de multicamadas da dança. Preston-Dunlop aponta que "uma apresentação de dança não comunica diretamente, mas contém camadas de elementos significantes criados pelos vários participantes no evento, incluindo o espectador" (1998: 7). Essas camadas são compostas de símbolos discursivos e afetivos, segundo Burt (1995). Gil profere que "uma coreografia comporta múltiplos estratos de tempo e de espaço" (2004: 71). Fernandes aponta que "[n] a cadeia significante, os movimentos da dança necessariamente multiplicam suas possibilidades de interpretação, ao invés de conceberem uma clara mensagem ou significado." (2007: 58). Parte dessas camadas são os vários canais de percepção e sensação, ativados na apreciação de uma dança: cinestésicos, visuais, auditivos (LACERDA, 2010: 74).

Tanto Preston-Dunlop (1998) quanto Sanchez-Colberg (1996) consideram que, num corpo dançando, estão em operação tanto discursos - sistemas de relações - semióticos quanto fenomenológicos. Lá estão signos presentes na interação humana, que incorporam pensamentos e sentimentos, em interrelação com a experiência fenomenal do corpo em dança, no aqui-e-agora, no espaço e no tempo experienciados (PRESTON-DUNLOP, 1998). Se chamarmos esses signos de agentes externos ao corpo, são agentes externos internalizados, "impingindo no corpo" (SANCHEZ-COLBERG, 1996: 46), incorporados - como diz Foucault (1988) - , ao mesmo tempo que esse corpo segue necessidades inerentemente físicas, aspectos da experiência em não significação, como movimentar-se, respirar, comer, suar, cansar, e também a fenomenalidade desse corpo 
em sua espacialidade própria, sua relação com o espaço circundante e com o espaço interno, a experiência em si de, por exemplo, uma transferência de peso. Gil diz: "há duas espécies de equilíbrio corporal: o puramente mecânico, de um sistema físico; e um outro que o movimento e a consciência introduzem no corpo. O movimento dançado nasce da colaboração destes dois equilíbrios" (2004: 17). O grau de modulação e também o grau de visibilidade entre as instâncias semiótica e fenomenológica irão variar de acordo com gêneros e estilos de dança, em diferentes épocas e contextos e também entre diferentes criadores.

Para não corrermos o risco de polarizar essas instâncias, seria interessante e saudável levar em consideração a proposta de Gil de um corpo paradoxal:

Consideramos aqui o corpo já não como um "fenômeno", um percebido concreto, visível, evoluindo no espaço cartesiano objetivo, mas como um corpo metafenômeno, visível e virtual ao mesmo tempo, feixe de forças e transformador de espaço e de tempo, emissor de signos e transsemiótico, comportando um interior ao mesmo tempo orgânico e pronto a dissolver-se ao subir à superfície. Um corpo habitado por, e habitando, outros corpos e outros espíritos e existindo ao mesmo tempo na abertura permanente ao mundo por intermédio da linguagem e do contato sensível, e no recolhimento da sua singularidade, através do silêncio e da não-inscrição. (ibid.: 56)

Visões baseadas em opostos, ainda hoje em dia, pautam o que se entende, se faz e se fala sobre dança, principalmente quando esta é confrontada com o teatro. Persistem oposições entre dança e teatro, dançarinos e atores, movimento e palavra, espontaneidade e representação, feminino e masculino.

[Hoje] há ainda a tendência de se considerar atores como os intelectuais do palco, e dançarinos como seres espontâneos capazes de entrar em contato com as forças escondidas do universo. Nossas mentes ainda se apegam à ideia de que dentro de cada homem há uma divisão entre mente e corpo. Corpo/mente, coração/cabeça - nessas construções binárias nós mais uma vez encontramos a dicotomia básica do masculino/feminino. (KERKHOVEN apud FERNANDES, 2007: 27)

Pensar em termos de polaridades leva a uma tendência a se pensar em fatos consumados, estados rígidos, em detrimento à qualidade de transformação permanente: "A explicação do mundo das formas de dança não deve ser confinada à enumeração de estados rígidos. Este mundo deve ser considerado como ondulações (transformações) vivas em constante mudança" (LABAN in BARTENIEFF apud FERNANDES, 2007: 36). 
Fernandes explica que:

para alcançar tal noção "dinâmica", Laban baseou suas teorias de movimento num "continuum entre polaridades", como mobilidade e estabilidade, e interno e externo. Como na simbólica correspondência entre sentimento e forma, movimento e notação, corpo e mente, tais polaridades se relacionam dentro de um todo unificador. (FERNANDES, 2007: 36).

O fato de Laban considerar a relação entre opostos como um processo transformativo, um "continuum de re-definições e buscas" (ibid.), nos faz conectá-lo aos pensamentos de Derrida.

\section{Pina Bausch e o Wuppertal Tanztheater: desestruturando e confron- tando polaridades}

Observamos a contribuição de Bausch para o alargamento do que pode ser entendido e aceito como dança, dos vários tipos de materiais que podem compô-la, especialmente no que concerne ao corpo e os materiais advindos dele, como movimento, voz, emoções, histórias pessoais, o próprio material fisiológico - pele, partes, cicatrizes, etc. -, com suas fragilidades, ideologias impingidas, fragmentações, fluxos de desejo e repressão e consciência corporal. Mais do que tentar unificar polaridades, Bausch as confronta e as "joga" na espiral tridimensional do Anel de Moebius. Assim, palavra-movimento, representação-apresentação, espontaneidade-condicionamento, homem-mulher, dança-teatro, dançarinos-plateia, circulam nesse Anel, forçando-se e redefinido-se uns aos outros, continuamente.

Perguntada se o movimento não é o bastante para o que ela quer dizer e, daí, precisar de palavras, Bausch devolve:

Palavras? Não posso dizer exatamente. Mas, então, novamente, ao contrário... poderia ser um movimento. É simplesmente uma questão de quando é dança, quando não é. Onde é que começa? Quando a chamamos de dança? Tem a ver, na verdade, com consciência, com consciência corporal, e a maneira pela qual formamos as coisas. Mas, então, não é preciso ter este tipo de forma estética. Pode ter uma forma bem diferente e ainda ser dança. Basicamente, quer-se dizer algo que não pode ser dito, então o que se faz é fazer um poema onde se pode sentir o que se quer dizer. E, então, palavras, acho, são um meio - um meio para um fim. Mas, as palavras não são o verdadeiro alvo. (BAUSCH in HUXLEY e WITTS, 1997: 59) 
A fricção entre dança e teatro ganha contornos de confronto, ao invés de complementaridade ou completude, nas mãos de Bausch.

Nas obras de Bausch, dança e teatro são trazidos ao palco como linguagem, mas não como uma totalidade de corpo-mente ou forma-conteúdo. Ao contrário, a natureza linguística daquelas artes é explorada como intrinsecamente fragmentada. Através da fragmentação e da repetição, seus trabalhos expõem e exploram a lacuna entre a dança e o teatro, a nível estético, psicológico, e social: movimentos não completam palavras em busca de uma comunicação mais completa; o corpo não completa a mente em busca de um ser total ou de uma presença mais completa no palco; mulher e homem não formam uma unidade liberando o indivíduo de sua solidão. (FERNANDES, 2007: 28)

Expectativas de uma unificação ou integração entre artes são postas por terra por Bausch. Expondo a lacuna, não só entre as artes, mas entre outras polaridades, Bausch consegue alargar o que pode ser considerado dança, ou espetáculo, e, como uma cadeia, questionar o que pode ser considerado teatro, mulher, homem, espetáculo, plateia.

O lugar de resolução desses confrontos, dessas lacunas expostas, é o próprio corpo: "O corpo dançante torna-se um instrumento de seu próprio questionamento como natural ou linguístico" (ibid.: 42). Aqui as instâncias fenomenológica e semiótica são postas mesmo em estado de confronto: “a linguagem da dança é a da crítica a qualquer esquema de princípios fixos e finais. É a linguagem do paradoxo, a linguagem da não-linguagem" (ibid.). Fazemos uma conexão com os conceitos de não-lugar de Bhabha e do espaço de labilidade de Derrida: uma arena onde acontecem os desencontros, os desafios, as redefinições, um lugar para o exercício do paradoxo.

Sobre a relação com os espectadores, Bausch tem consciência da relação de poder existente entre estes e a obra apresentada (espetáculo, dançarinos). Noções de valor monetário - o ingresso pago - e de valor simbólico - o status internacional da companhia, subsidiada por um município de um país desenvolvido e reconhecida internacionalmente -, expectativas por parte do espectador de ser divertido ou enlevado e de presenciar o virtuosismo dos dançarinos e a excelência da produção etc., são questões postas em jogo.

Em uma cena de Kontakhof (1978), os dançarinos assumem temporariamente o papel de plateia, assistindo - e julgando - o que está em cena, assumindo o olhar de voyeur e de comprador. Na visão de Fernandes, isto é mais um aspecto do que está "em jogo" na espiral tridimensional do Anel de Moebius que Bausch faz funcionar, trabalhando a desconstrução do medium da dança em sua recepção pelos espectadores.

Aplaudindo-se a si mesmos, os dançarinos atuam o papel do públi- 
co e incorporam seu poder. A dança passa a discutir criticamente a relação entre seus executores e espectadores, todos incluídos nesta cadeia significante em busca de um significado social e estético - a atenção e o reconhecimento alheios. Neste contexto, as dicotômicas relações entre indivíduo e sociedade, autêntico e mecânico, dançarinos e público, arte e vida, tornam-se cada vez mais sobrepostas, entrelaçadas e reciprocamente desafiantes e transformadoras. (FERNANDES, 2007: 73)

Outra expectativa frustrada é a de ser saciado por um espetáculo cheio e movimentado. As pausas e as inações são muito presentes e funcionam tanto para criticar o meio da dança e a relação com os espectadores quanto nas temáticas tratadas. Pausas e imobilidades são particularmente desconfortáveis para o espectador:

O público quase não pode suportar pausas no teatro. (...) Beckett; ele deu durações exatas para as pausas porque sabia que os diretores e os atores têm medo delas. Um ator já fica tenso de medo quando não pode mover-se ou dizer qualquer coisa por apenas dez segundos. É contra o acordo. Há um acordo, uma regra: Eu pago e você trabalha. $\mathrm{O}$ ator trabalha e eu, como espectador, pago. Mas eu quero que ele sue, este ator, pelo dinheiro que eu estou lhe pagando. Se ele não fizer nada por algum tmpo, significa que está relaxando, o porco, com o meu dinheiro, e eu não vou aceitar isso." (MÜLLER apud FERNANDES, 2007: 120)

Arriscamos dizer que esse desconforto deve-se ao fato de que a pausa, o gap, é o próprio espaço de devir, não lugar, entre-lugar, centro faltante, espaçamento, rastro, ausência.

Podemos reconhecer que a dança-teatro, gênero de dança que Bausch integra e ajudou a desenvolver e difundir, é, por excelência, um espaço entre polaridades e um entre-lugar. Fernandes diz que é no "hífen" entre dança e teatro que a dança-teatro reside:

[...] é o "entre", a transição, o sistema conjuntivo que liga diferentes estruturas corpóreas e destas para o espaço externo e de volta para o espaço interno. É a arte da fronteira, do abismo entre sono e vigília; é dançarino cantando, atriz dançando, tijolos caindo e maçãs voando (Palermo, Palermo, Bausch); é um constante transitar entre os muitos "eus" e "tus", desafiando e desestabilizando identidades a partir da relação com o "outro", o "diferente". (FERNANDES, 2006: 375)

Traçamos o início da dança-teatro com a prática e pensamento de Laban, não sem 
motivo mencionado anteriormente e relacionado a Derrida no que diz respeito a ocupar o espaço entre polaridades. É impressionante que ambos os autores utilizem o termo labilidade para evocar esse espaço de desestabilização, de devir. Alguns fatos fazem de Laban o precursor da dança-teatro: considerar o dançarino como um ser integrado que "pensava-sentia-fazia” (BARTENIEFF apud FERNANDES, 2007: 27); entender a dança como algo que é experienciado e entendido, sentido e percebido pelo indivíduo como um ser completo, não como algo com um enfoque puramente cognitivo ou intelectual (OSBORNE apud FERNANDES, 2007: 27); a criação de um sistema de notação (a Labanotation) apropriado ao entendimento da dança como linguagem cinestésica ou simbólica, diferente de expressão espontânea e de linguagem discursiva, evidenciando o fato de que a dança tem um conteúdo significativo, compreensível (FERNANDES, 2007: 27).

A dança-teatro também traz como bagagem uma herança de mão dupla das vanguardas teatrais e de dança (SANCHEZ-COLBERG, 1996), mas, principalmente, no que se fez no contexto em que estava presente a dança pós-moderna norte-americana, iniciada nos anos 1960, especialmente na cidade de Nova York. Nesse contexto, poetas e artistas plásticos dançavam, dançarinos participavam de performances e happenings de artistas plásticos, dançarinos e não dançarinos atuavam numa mesma obra artística, dançarinos escreviam e também dirigiam filmes. A relação entre as artes e os espectadores foi questionada e, gradativamente, a preocupação principal com o produto final e seu efeito aurático foi mudando de foco, para incluir o processo.

Bausch foi influenciada por Laban, tanto em sua formação em dança quanto em sua prática artística inicial, pois, em ambos, trabalhou juntamente a Kurt Jooss, ex-aluno e colaborador de Laban. Também morou dois anos em Nova York nos anos sessenta, estudando e dançando. Bausch incorpora e altera essas influências, mas de uma forma crítica, conforme Fernandes (2007: 23). As peças de Bausch materializam essas características, na forma de um caos grupal generalizado, sob certa ordem, favorecendo processo sobre produto e provocando experiências inesperadas em dançarinos e plateia, sem rejeitar a grandiosidade teatral (FERNANDES, 2007: 23).

As significações que brotam em suas peças emergem, dissolvem-se e sofrem mutações, funcionando numa constante transformação. Na temática de suas obras, movimentos e elementos da vida diária são incorporados com o intuito de expor que são tão artificiais quanto a apresentação cênica. O que surge de espontaneidade, acontece como um resultado do recurso das repetições, mecanismo que faz girar a espiral tridimensional do Anel de Moebius de Bausch. O que impele seu giro é uma "constante incompletude, busca e transformação dentro de um pensar-sentir-fazer fragmentado, ao invés de integrado." (ibid.: 29). Conectamos essa constante incompletude com o centro faltante de Derrida.

Partindo do princípio de que o corpo individual é um corpo social - uma construção a nível psicofísico, constantemente permeada e controlada por repetitivas normas de disciplina em meio a relações sociais de poder - Bausch radicaliza na dissecação de nossos mapas corporais, adquiridos através da repetição desde a infância. Experiências 
passadas, suas e de seus dançarinos, tornam-se matéria prima para o desenvolvimento de suas obras. Essas experiências são, inicialmente, reconstruídas e, posteriormente, moldam a forma estética. Mais tarde, provocarão "diversas e imprevisíveis experiências no dançarino e em sua platéia, aumentando as possibilidades de interpretação e associação pessoais" (ibid.: 51).

Um outro tema tratado por Bausch é o próprio medium da dança: expondo os processos de aprendizagem de dança (especialmente o balé clássico) que utilizam a repetição como meio de atingir a perfeição; mostrando os bastidores de ensaios no aprendizado de uma sequência de dança; mostrando a falha como uma possível opção de dança, além da almejada perfeição; problematizando a questão do corpo ideal e perfeito para a dança.

Critica-se a natureza positivista do aprendizado do balé, nascido da falta de perfeição motora, indo em direção a uma perfeição e a um virtuosismo e total controle do corpo. Fernandes (ibid.: 108) conecta isto a Foucault, crítico radical da estrutura positivista de conhecimento e controle/poder sobre o corpo. Esse pensamento também está ligado à medicina, que trabalha a partir da falta de saúde. Em Kontakthof esse processo de aprendizado através do controle é exposto, repetido e desconstruído. Isto também está exposto no processo tradicional de aprendizado de sequências de dança para um espetáculo, similar ao do aprendizado do balé, no qual perfeição e erro se constituem em polaridades claras: erro é falha; perfeição é o alvo a ser atingido. A falha na sequência coreográfica pode se mostrar muito mais verdadeira e interessante, como também as falhas no corpo podem sair do seu lugar escondido e tornar-se o assunto, ou um dos assuntos, da peça, como em 1980, obra na qual os dançarinos expõem suas marcas, advindas de acidentes em suas vidas cotidianas e de ensaios e apresentações (ibid.: 87).

Outra temática muito forte nas obras de Bausch é a inabilidade de uma comunicação bem sucedida, da completa expressão e percepção de um único significado, seja entre dançarinos no palco, seja entre estes e a plateia. Em uma primeira tentativa mal sucedida de comunicação, uma outra é repetida, não obtendo sucesso, e assim por diante (ibid.: 111).

Bausch estrutura suas cenas através da técnica da colagem com livre associação: pequenas cenas ou sequências de movimento são fragmentadas, repetidas, alternadas, ou realizadas simultaneamente, sem um desenvolvimento definido na direção de uma conclusão resolutiva (ibid.: 26). A repetição é, ao mesmo tempo, tema, artifício coreográfico e estrutura composicional. Na estruturação propicia que:

a) o tempo medido e pago seja desestruturado, gerando momentos de suspensão, nos quais os dançarinos questionam e desmontam as expectativas da plateia;

b) as peças estejam em constante processo, não havendo necessariamente uma separação entre processo criativo e produto final, expondo o processo técni- 
co e as imperfeições da dança e dos dançarinos e o valor comercial da dança em relações de poder entre os dançarinos e o público (ibid.: 78);

c) significante e significado se confundam;

d) seja feita a desconstrução de: linearidades de memórias e associações de dançarinos e de espectadores; uma identidade ou fixidez da história do sujeito; a movimentação previsível de corpos formados pela técnica do balé e o método socrático de fazer perguntas para descobrir uma verdade (ibid.: 139); significados literais das palavras; vocabulários impostos nos corpos dançantes (o social, do cotidiano, e o estético, dos vocabulários de dança);

e) a dança incorpore e discuta sua natureza inerentemente paradoxal;

f) as imagens se imprimam e se transformem na memória do espectador, "resistindo à qualidade efêmera da dança e permitindo novas maneiras de ver." (ibid.: 64);

g) a dança e seus participantes se reconstruam a si mesmos.

Podemos perceber a diferência agindo: linearidades, polaridade, significações, todas postas em movimento e transitoriedade na espiral tridimensional do Anel de Moebius. "Em cada peça sempre há o seu oposto; assim como na vida. Que também tem algo a ver com tentar encontrar uma harmonia." (BAUSCH in SERVOS, 1999).

\section{William Forsythe: polifonias deslizantes}

Polifonia, multidirecionalidade, descentramento, desestabilização são palavras que se ligam ao trabalho de Forsythe. O termo polifonia Forsythe encontrou em suas leituras de Barthes. Propomos que seu trabalho possui vários focos de polifonias, trabalhados autônoma e entrelaçadamente: no corpo dançante individual; na relação entre os dançarinos e estruturação das obras; na relação com o observador/espectador.

Os três pilares sobre os quais o trabalho de Forythe se desenvolveu foram: formação corporal no vocabulário do balé clássico, as teorias de Laban e a leitura de autores estruturalistas e pós-estruturalistas franceses (SERVOS, 1999; NUGENT, 1998; 2003).

Durante sua formação, Forsythe ficou bastante impressionado com o papel que George Balanchine teve para a construção do neoclassicismo no balé, tirando o peso do clássico e organizando-o de modo mais musical que visual (SERVOS, 1999).

O contato com as teorias de Laban aconteceu durante um período em que permaneceu sem fazer atividades físicas, devido a um problema no joelho, em 1971. É in- 
teressante que a ausência (um rastro, um espaçamento) da atividade de dançar tenha promovido um espaço para uma renovação de suas ideias e vontades para a dança. A ideia de que qualquer movimento pode se tornar um movimento de dança foi decisiva. $\mathrm{Na}$ Corêutica, parte correspondente à Harmonia Espacial, ele descobriu que "o corpo dançante poderia ser liberado de sua organização centralizante e libertado para se mover através de cinesferas sem limites. Ele começou a gerar sistemas de movimento próprios, que, ao longo dos anos, têm se tornado crescentemente complexos" (NUGENT, 2003: 41). Percebemos uma conexão muito forte com o conceito de centro faltante de Derrida, mostrando-se uma ferramenta para novas possibilidades de investigação do corpo dançante, com a liberação do centro trabalhado na técnica do balé e também dos centros de gravidade e levitação, apontados por Laban (1978).

Quanto aos autores que Forsythe leu, Servos (1999) chama a atenção para os conceitos apontados por Barthes, nos anos iniciais, de desmontar e rearranjar, e sua visão de uma polifonia de signos e símbolos em ação na dança e no teatro contemporâneos. De fato, quando apreciamos algumas obras de Forsythe, vemos materializadas as ideias de desmontar e rearranjar. De Foucault, não podemos dizer especificamente o que o influenciou; entretanto, fazemos uma ligação com seu trabalho quando Foucault fala que o poder é onipresente, mas não é exercido de um ponto central, e, sim, da relação entre vários pontos, vindos de vários lugares e constantemente instáveis (FOUCAULT, 1988: 103). Com relação a Derrida, não temos certeza de que Forsythe o tenha lido, mas as probabilidades são muito grandes. Podemos estabelecer muitas conexões entre sua obra coreográfica e os conceitos de desconstrução, centro faltante, labilidade, rastro, espaçamento.

Forsythe também mostra interesse por áreas aparentemente não relacionadas (teoria literária, física, poesia, matemática, mito, ciência), justapondo-as em seus trabalhos (NUGENT, 2003: 43).

De acordo com Servos (1999), Forsythe vê o teatro e a dança mais como um projeto de pesquisa com resultados incertos, um processo no qual as variáveis podem ser mudadas a qualquer momento, em qualquer direção. $\mathrm{O}$ resultado é uma liberdade de escolha que funciona para o coreógrafo, para o dançarino e também para os espectadores. O objeto de sua pesquisa é a relação de um signo com outro, signos previamente explodidos em partes individuais e reorganizados puramente por princípios físicos de composição, não por uma narrativa ou por personagens. Nugent (1998: 27) esclarece que, a despeito da vastidão do que ele absorveu, seu ponto de partida é o próprio corpo. Servos (1999) aponta vários aspectos de seus procedimentos:

a) decupando ao extremo elementos do vocabulário do balé, Forsythe formava séries em repetição infindas, que ele manteve refinando e estendendo, através de artifícios coreográficos como retroceder, adicionar, subtrair etc.; assim, o conteúdo narrativo é dissolvido e a dinâmica do movimento so- 
bressai;

b) respeitar o tempo próprio exigido por cada evento faz com que se tenha maior liberdade ao abordar a música;

c) o emprego de tempos musicais e de dinâmicas diversos permite que linearidades sejam apagadas;

d) o uso do espaço é des-hierarquizado, conferindo igual importância a onde quer que se inicie o movimento ou onde o finalize.

Assim como Laban, Forsythe aplicou as teorias da Corêutica ao corpo formado pelo balé. Descobriu que "desfazendo-se da coluna ereta e da rotação externa [o en dehors] e eliminando as hierarquias de partes do corpo, de dançarinos específicos e de espaços no palco, novas oportunidades entrariam em jogo" (NUGENT, 1998: 29). Aqui, fazemos duas conexões: uma, com Merce Cunningham, um dos pioneiros na des-hierarquização, tanto de partes do corpo quanto de locais no espaço de apresentação; outra, com o conceito de labilidade (de Derrida e de Laban) e o de centro faltante. Rubidge (1999: 46) identificou que a abordagem de Forsythe na Corêtica difere radicalmente da original: "Informado por princípios pós-modernistas, ela desestabiliza molduras de referências espaciais padrão, fragmenta unidades e desafia usos prescritivos de corpo-espaço. Em resumo, ele chuta a bola coreográfica para fora de área."

Sua coreografia parte da proposição de que a linha se torne multidirecional. "Suponha que a aresta externa torce em direção à aresta interna. Suponha que o centro forte a partir do qual todas as linhas do balé fluem é desestabilizado. O que pode emergir?", propõe Forsythe (in NUGENT, 1998: 26). Dessa forma, os corpos de Forsythe conectam curvas e ângulos em formas que surpreendem o observador. Forsythe foi gradualmente saindo da orientação vertical, e arriscando-se cada vez mais na desestabilização, na labilidade. Assim como Laban havia enfatizado que o que importa não são os pontos no espaço, mas, sim, o caminho entre um e outro, a transitoriedade, Forsythe experimenta várias possibilidades.

O descentramento é levado ao ponto de se permitir considerar como centro qualquer parte do corpo, com centros cambiantes, para que "o corpo seja possibilitado a concretizar seu potencial total de movimento"; seu papel, como coreógrafo, "é continuar estendendo esta capacidade percebida" (NUGENT, 2003: 41).

Uma boa visualização dessas características é o próprio Forsythe dançando. Em Solo (1995), percebemos todo o trabalho de isolamento de partes e de diversas relações entre estas, diversos percursos espaciais iniciados pelas mesmas e executados sucessiva e simultaneamente, diversas variações dinâmicas e a desestabilização do eixo e suas consequentes descobertas de percursos inusitados.

Em The The, um dos mais intimistas de seus trabalhos, duas dançarinas estão em 
cena, lado a lado, no nível baixo, na base sentada, na direita baixa do palco (ponto de vista dos dançarinos). O que mais chama a atenção é o contraste entre o desenho de suas pernas, trabalhadas pelo balé, estendidas e em ponta, cheias de "S"s, numa posição do cotidiano, desassociada do balé, do dia a dia. Nesse contexto, aquelas pernas "virtusísticas" do balé podem ser percebidas como "aleijadas", ainda mais quando o movimento isolado de seus troncos e braços "desconjuntam" o corpo, dando uma sensação vívida de fragmentação. Fortemente, o corpo - desenho, forma e história de sua formação (aulas de dança, coreografias dançadas, experimentos realizados, etc.) - é o próprio assunto da coreografia, o corpo como um rastro movente.

Em One Flat Thing, Reproduced (2000), o observador/espectador é bombardeado com uma miríade de pontos energéticos em movimento: partes mínimas do corpo, partes maiores, o corpo como um todo, mesas sendo empurradas, mesas como suporte, mesas como divisores dos níveis espaciais por onde os dançarinos transitam. Os percursos percorridos por essas partes corporais e os corpos como um todo fazem da composição do trabalho um refinadíssimo quadro que desafia a percepção do observador. As relações de dinâmicas parecem átomos em ebulição, fenômenos se fazendo e se desfazendo, gerando as ações que se alimentam sucessivamente.

Em Enemy in the Figure (1989), a escala é grande, assim como a carga de energia que permeia o trabalho. Com o uso cambiante de cenário e objetos de cena, utilizados de maneira não narrativa, insólita até, o descentramento trabalhado no corpo vem com uma energia raivosa, aliada à poderosa trilha sonora. É um trabalho mais sombrio, literal (pelas sombras) e metaforicamente.

In the Middle Somewhat Elevated (1987) foi comissionada por Rudolf Nureyev, quando diretor do Paris Opera Ballet, e criada em cima do corpo de Sylvie Guillem. É um pas de deux cheio de tensão e contrapesos, no qual o vocabulário e o virtuosismo técnico do balé são celebrados, porém, em um contexto de labilidade, que fascina e intriga o observador. A trilha sonora eletrônica de Thom Willems - colaborador longevo de Forsythe - é um componente poderoso, soando como se os acordes metálicos iniciais de A View to a Kill de Duran Duran fossem postos em série numa composição erudita contemporânea. Muito do fascínio dessa obra deve-se à participação de Guillem, tanto no processo quanto na execução da obra. Ela é virtuosística na técnica do balé e tem uma interpretação vigorosa, porém seu talento para trabalhar com coreógrafos contemporâneos é uma característica que a difere de outras estrelas do balé, tendo a capacidade de entrar totalmente na proposta e no jogo desses coreógrafos. Tanto é que, na interpretação desse trabalho, outras dançarinas, apesar de possuírem a técnica que o trabalho demanda, não chegam às arestas que Guillem chega nas desestabilizações e não alcançam a ironia e a atitude blasé com que lida com seu material.

Eidos: Telos (1995) foi desenvolvido ao longo de uma exploração de dois anos em cima dos mitos gregos, geometria e matemática. Forsythe explica que a chave para assistir a ele é o alinhamento. Uma vez entendido isto, torna-se possível ver todas as formas de alinhamentos passando através do tempo e do espaço. $\mathrm{O}$ alinhamento pode nem sem- 
pre estar ao longo (como na linha do balé); frequentemente estará através e envolverá tanto similaridade quanto diferença na movimentação, direção e ímpeto. Pode variar, também, em escala, do grande ao minúsculo (NUGENT, 1998: 30).

Várias das obras de Forsythe são remontadas para companhias de balé e algumas são especialmente comissionadas. Em nossa opinião, o resultado não apresenta, em sua plenitude, a desestabilização trabalhada com seus dançarinos. A propósito, Forsythe atrai dançarinos de diferentes países e escolas de formação. Segundo Nugent (2003: 41), sob sua tutela, eles tornam-se extraordinariamente articulados em sua coreografia, interpretando-a com rigor, precisão e uma consciência de cada músculo em seus corpos. Eles o dançam como se fossem donos do movimento.

Isto deve-se a uma gama de exercícios e tarefas de improvisação que Forsythe foi construindo e acumulando ao longo dos anos e que repassa aos seus dançarinos. Uma maneira encontrada para repassar aos recém ingressados esses exercícios foi um tutorial hightech (Improvisation Technologies 1) desenvolvido quando diretor do Ballett Frankfurt (RUBIDGE, 1999: 46). Em uma versão com conteúdo e funções reduzidas, o tutorial foi produzido e lançado em formato de CD-ROM (Improvisation Technologies: A Tool for the Analytical Dance Eye, 1999) para comercialização, visando proporcionar a dançarinos, tanto iniciantes quanto com mais experiência em improvisação, a vivência de seus exercícios e alargar sua gama de movimentação. Vemos as tecnologias de improvisação compiladas por Forsythe como um rastro dos seus processos criativos, que podem ser vivenciados por outros corpos.

Forsythe estruturava seus trabalhos inicialmente revisitando o repertório do balé clássico, desarranjando-o através da técnica da colagem. Servos (1999) comenta que, gradualmente, isto foi dando cada vez mais espaço para a improvisação, entendendo-a como um sistema de possibilidades para se jogar. Em média, 70\% da coreografia final são fixados e o restante, deixado a cargo da improvisação. Isto traz mais imprevisibilidade às apresentações e também uma certa fragilidade, o que confere um frescor ao trabalho, e, ao mesmo tempo, exige uma grande responsabilidade por parte dos dançarinos. A noção de transitoriedade ganha uma grande importância, pois torna-se inerente ao próprio trabalho. A fluidez da dança sentida e vista em cena é também aplicada a tudo o que está em jogo no palco: iluminação, objetos de cena e cenário.

Várias atividades simultâneas e diferentes compõem a estrutura de suas obras. Por vezes, torna-se difícil acompanhar tudo o que está acontecendo no palco e, de tudo aquilo, fazer um sentido. Cada pessoa verá e perceberá diferentemente. Vários elementos podem estar justapostos: relações do próprio movimento dançado entre si ou do movimento dançado com outros meios, como música, elementos de cenário e objetos de cena, imagens projetadas, texto. A noção de centro faltante, em atuação tanto na abordagem do corpo dançante quanto na estruturação das obras, também reverbera no espectador, cabendo a este escolher onde concentrar seu foco e tecer relações entre o que acontece no palco, pois nada é oferecido linearmente. O espectador põe para funcionar sua espiral tridimensional do Anel de Moebius. 
A questão da perspectiva e o ato de ver são assuntos de extrema importância para Forsythe: "A percepção de uma obra de dança é modificada pelo contexto no qual esta é apresentada" (FORSYTHE in SIEGMUND, 2001b: 73). Em Artifact (1984), providenciou que a cortina descesse repetidamente no meio das cenas em andamento, causando um grande estranhamento e incômodo ao público. Estranhamento porque não se sabia se o espetáculo havia terminado ou não. Incômodo porque a expectativa de um espetáculo que valesse o dinheiro do ingresso, com promessas de divertimento, elevação do espírito, belas atuações dos dançarinos - ideias herdadas do Iluminismo - foi atrapalhada. Artifact agora é vista como um clássico, opina Siegmund (ibid.), "ela quebrou com o nosso continuum de percepção e nos fez conscientes de quão gananciosos nós fitamos o palco. Com efeito, Forsythe questionou o quanto a audiência queria assistir - sem interrupções, por favor - belos dançarinos ocupados com um pas de deux".

Sua subversão está apontada principalmente para a perspectiva central, originada na pintura renascentista, vindo, subsequentemente, a dominar outras formas artísticas, incluindo o balé. Ela presume um olho estático, liberto de um corpo físico, com linhas de visão sempre estáveis encontrando-se num ponto de fuga centralizado no plano de fundo da composição. Um mundo hierarquicamente organizado se estende para um observador que domina a perspectiva central, que pode usá-la como um espelho para auto-reflexão. Não coincidentemente, o desenvolvimento da perspectiva central está associada à ascensão concomitante do humanismo. Seus críticos iniciais objetaram que o olho não é um foco de câmera estático, mas sempre em movimentação.

Forsythe aborda essa tradição de duas formas. Primeiro, em termos de estética de produção, subvertendo a identidade do balé e seus códigos de movimento, na relação com o corpo dançante e na estruturação das obras. Segundo, em termos de estética da recepção, questionando o sujeito que olha.

Vários de seus trabalhos são feitos para espaços convencionais de teatro. Outros, para espaços alternativos. Em Kammer/Kammer (2001), apresentado no Bockenheimemer Depot, um antigo depósito de bondes em Frankfurt, o cenário compõe-se de quartos de hotel, com dois dançarinos vivendo personagens e o restante deles fazendo pequenas coreografias. Além do cenário, há telas projetando imagens editadas e ao vivo. O desfile de imagens fica em primeiro plano e as ações dos dançarinos, em segundo. As ações são parcialmente cobertas e o público é disposto pelo espaço. Os pontos de vista são cambiantes e o que é oferecido à visão também difere para cada espectador; logo, a recepção e a construção de possíveis significados são um processo muito particular para cada um (SIEGMUND, 2001c: 44-45).

Endless House (1999) é composto de duas partes, cada uma realizada em um espaço diferente: o palco da Ópera de Frankfurt e o Bockenheimemer Depot. O primeiro lida com a perspectiva central e o segundo, com a visão multidirecional. O espetáculo é composto de coreografia, texto (trechos de citações de Emily Brontë, Charles Manson, entre outros), trilha sonora para cada espaço, cenário com longos metros de tecido e iluminação com cores fortes. Propositalmente, os espectadores são levados a experimentar 
essas duas formas de recepção e fruição da dança (SIEGMUND, 1996: 46).

Em The Bouncy Castle (2001), uma grande instalação em forma de castelo feita com material de espuma, os espectadores entravam e vivenciavam corporalmente a relação com esse lugar, com essa determinada textura. Sobre esse trabalho, Forsythe comenta que "se você não engajar o seu corpo, você não consegue entender. É um experimento cognitivo..." (FORSYTHE in SIEGMUND, 2001c, 74). Aqui as polaridades entre espectador e executor são decididamente borradas.

\section{Meg Stuart e sua companhia Damaged Goods: dançando estados}

Meg Stuart é norte-americana, mas seu trabalho teve maior repercussão na Europa. É um tanto nômade, passando alguns anos em cidades europeias (Bruxelas, Berlin, Zurich) que lhe dão patrocínio para desenvolver seus trabalhos. Podemos dizer que esse nomadismo reflete-se em seu trabalho com a exploração da diferença em diversos aspectos:

a) na variação de modos de apresentação, que pode passar pela dança, instalação e performance e a variação dos elementos utilizados (vídeo, texto, ambientação); pode acontecer tanto ao longo de um trabalho específico, como Appetite (1998), quanto entre obras diferentes;

b) na bagagem diversa dos colaboradores, compostos por dançarinos, atores, artistas visuais e de vídeo, designers, músicos e teóricos;

c) na rotatividade nômade dos colaboradores: contribuem intensamente para determinado projeto, cedendo o lugar, em um projeto seguinte, para outras ideias, outros elementos e outros colaboradores;

d) nos dançarinos e atores, com tipos físicos, procedências e formações corporais diversas;

e) entre espetáculos: como cada um inicia de uma proposta ou colaborações diferentes, cada trabalho tem uma "cara" bem diferente da do outro.

Assim como Bausch e Forsythe, o corpo é o ponto de partida e o laboratório de Stuart, que o considera como "uma entidade física" (AYERS, 1999: 9). Seu interesse na decupagem e desconstrução do corpo faz com que, no ato da apresentação, a qualidade tátil esteja muito presente.

Na visão de Schlicher (2001: 34), Stuart representa a artista obsessiva, atacando, 
através de sua pesquisa de movimento, as convenções de normalidade/anormalidade em um nível psico-físico, revelando a vulnerabilidade do corpo deformado e defeituoso. Há duas abordagens principais em seu trabalho: a referência à história das Artes Visuais e a análise do movimento cotidiano, especificamente do movimento e comportamento corporal em situações extremas, de pessoas idosas, de pessoas deficientes. Seu interesse nesse contexto não é o de copiar os movimentos, mas usá-los como readymades. Essa fascinação pelo corpo e movimento deformados revela uma afinidade com artistas plásticos como Francis Bacon. Para Stuart, a deformação funciona como uma metáfora para sua percepção e experiência do mundo, um espaço de diferência.

Stuart observa, fragmenta e transforma formas e movimentos corporais. Ela busca os defeitos do corpo, as articulações histéricas e narcisistas do corpo humano, a escondida estrutura psicológica da deformação anatômica. Ela explora a falha da comunicação humana, assim como Bausch. Seus corpos são geralmente envolvidos em ações repetitivas e isoladas, com movimentos maníacos, e estados de exaustão depressiva. Gradualmente, essa carga física da movimentação foi mudando para uma direção em que, mais e mais, se vê menos e menos dança em sua forma mais facilmente reconhecível.

Disfigure Study (1991) foi o primeiro trabalho que lhe deu um reconhecimento grande. Teve como ponto de partida a dissolução da figura humana que Francis Bacon desenvolveu em suas pinturas. Possui uma versão em trio e uma solo. Tendo assistido à própria Stuart dançando, na versão solo, pudemos perceber uma qualidade corporal de descentramento, desarranjamento e dissolvimento do corpo, que desafiam a ideia de um corpo uno, sensual, ou de um corpo-objeto, principalmente em se tratando do corpo de uma mulher, semidesnudo, atlético e desejável, exposto em cena.

Em Soft Wear (2000), Stuart passa por poses e flashes, incialmente percebidos como do cotidiano - um cruzar de braços, um coçar de cabeça, uma transferência de peso de uma perna para outra etc. - e repete-os em estados corporais diferenciados, estados que sugerem uma dissolução e um desconforto oriundos de um aprisionamento no próprio corpo, que faz com que se olhe para esse corpo com uma outra disposição, na qual o estranhamento ocupa uma grande parte.

Para Stuart, "dança é um lugar para tentar coisas com as quais você não está necessariamente confortável" (in PEETERS, 2011: 150). Entrando nesse entre-lugar, Stuart e seus dançarinos tentam rearranjar experiências e legados do meio da dança em si, experiências da vida contemporânea e experiências de estados corporais diferenciados. No comentário sobre Visitors Only (2003), feito por Fernandes e Moura (2004), podemos vislumbrar como esses estados corporais diferenciados compõem a cena:

Residindo numa zona limítrofe, Visitors Only, com o grupo Damaged Goods, sob a direção de Meg Stuart, articula linguagens como teatro, dança e música. Há uma série de pequenas narrativas, muitas vezes simultâneas que acontecem numa casa "estripada", isto é, uma casa rasgada em corte horizontal, que ocupa toda a extensão do pal- 
co, em dois pavimentos, com portas, janelas e passagens estranhas e não ergonomicamente pensadas para seres humanos.... pelo menos não para "normais". Este espaço anormal se relaciona intensamente com seres, aparentemente normais, mas esquizo-mecanicamente alterados pelos processos de modernização, pela tecnologia, pela sede de sucesso, pela perda da doçura, da espontaneidade, que assola e coloniza corpos. Isto está explícito no embate constante entre corpo mecânico-newtoniano e corpo organo-quântico. (FERNANDES e MOURA, 2004)

Uma cena em particular desse espetáculo, com os dançarinos em estado de tremor, cinestesicamente atinge o espectador. Stuart relata (apud PEETERS, 2011) que ela e seus dançarinos fizeram um workshop específico para essa técnica de tremor, que leva a um estado de transe e meditação. Essa desestabilização da sensação e da consciência do corpo, através da mudança de estados corporais, é um motor, para Stuart, para novas descobertas.

Violet (2012) é todo estruturado em mudanças de estados corporais, individuais e coletivas, que necessitam de um tempo estendido para se desenrolar. Aos espectadores, só resta testemunhar o surgimento, desenvolvimento e transformação desses estados, o que muitas vezes provocam desconforto e também sonolência, por um lado, e perplexidade, por outro. $\mathrm{O}$ acompanhamento sonoro, feito por um músico/programador eletrônico, oferece uma esteira de sons que ora acompanham e enfatizam, ora contrastam, com o desenrolar desses estados. Um clima algo opressivo permanece no ar, como se estivéssemos presenciando a fase posterior, ou a sobrevivência, a uma catástrofe. Nesse espetáculo, possíveis significados podem até ter a iminência de surgir, porém se esquivam e se deslocam quando um novo estado corporal começa a ser ativado.

Stuart também desafia o próprio medium da dança, acolhendo e utilizando procedimentos de outras disicplinas, como as artes visuais e o vídeo. Para Ayers (1999), ela frequentemente cruza a linha divisória entre dança e arte da performance e seu trabalho é altamente engrandecido por causa disso.

Em Are We Here Yet? (2011) - livro editado por Jeroen Peeters - Stuart e seus colaboradores testemunham sobre o impacto das obras e processos em seus próprios corpos. Com Stuart, os colaboradores efetivamente passam por uma experiência corporal, o que confere uma qualidade diferenciada aos produtos resultantes. Percebemos o corpo funcionando como o próprio espaço entre polaridades, se considerarmos que diferentes áreas artísticas e do conhecimento geralmente configuram-se como polaridades entre si.

Os espaços físicos onde as obras de Stuart são apresentadas podem variar, indo de um espaço teatral mais convencional até espaços bem específicos. Consequentemente, a relação com os espectadores é sempre alterada, por conta disto. Mesmo nos espaços mais convencionais, dependendo do colaborador artista visual ou de vídeo em questão, o espaço pode estar recoberto de argila úmida, que, ao desenrolar do espetáculo, vai en- 
durecendo e partindo (Appetite). Pode estar forrado de peles. Pode estar repleto de telas de vídeo (Splayed Mind Out, 1997). Pode ter o cenário de uma sala, dentro de uma estrutura giratória grande que faz o cenário girar com os dançarinos dentro (Replacement, 2006). Pode ser o cenário de um apartamento muito estranho (Visitors Only). Pode ser este mesmo cenário num espaço de rua (Revisited). Pode ser uma instalação, com vários ambientes e saídas, onde o público efetivamente é parte da obra (Highway 101). Enfim, a gama de possibilidades é grande.

A percepção e resposta do público são desafiadas por todos esses elementos: desde a pesquisa corporal e seus estados cambiantes até os elementos extrínsecos à dança que com ela dialogam e pelo ambiente em que a dança acontece. Por exemplo, em Appetite, Stuart decide deliberadamente não terminar o espetáculo, mas acender as luzes do teatro, uma convenção teatral de que o espetáculo terminou. Já em Highway 101, os diferentes espaços de cena e de saída propostos (sugerindo espaços de realidades diferentes) são combinados com diferentes modos de assistir, olhando para cima para uma cena que acontece em cima de um telhado de vidro, deitado sobre a barriga para ter a visão de baixo, etc.

\section{Consideraç̧ões finais}

Ter entrado um pouco nos mundos coreográficos desestabilizadores (e fascinantes) desses artistas nos faz acreditar na desestabilização como via de mudança e transformação, que é o que a desconstrução propõe. Acredito que a contribuição deles é grande para nos percebermos em relação à contemporaneidade.

\section{Referências bibliográficas}

ADSHEAD, Janet. (ed.). Dance analysis: theory and practice. Londres: Dance Books, 1988.

AYERS, Robert. "Meg Stuart: not really dance at all” In Dance Theatre Journal, vol.15, $\mathrm{n}^{\circ} 1$, pp. 8-11, 1999.

BARTENIEFF, Irmgard. Body Movement: Coping with the Environment. Pennsylvania: Gordon and Breach Science Publishers, 1980.

BHABHA, Homi K. O Local da Cultura. Belo Horizonte: Ed. UFMG, 1998.

BANES, Sally. Terpsichore in Sneakers. Post-modern dance. New England: Wesleyan University Press, 1987.

. Greenwich Village 1963: avant-garde, performance e o corpo eferves- 
cente. Rio de Janeiro: Rocco, 1999.

BURT, Ramsay. The male dancer. Londres: Routledge, 1995.

DERRIDA, Jacques. Gramatologia. São Paulo: Perspectiva, 2006. . Writing and Difference. Londres: Routledge, 2008.

FERNANDES, Ciane. O corpo em movimento: o sistema Laban/Bartenieff na forma-

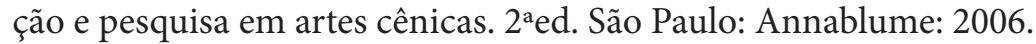
. Pina Bausch e o Wuppertal Dança-Teatro: repetição e transformação. $2^{\text {a }}$ ed.

São Paulo: Annablume, 2007.

FERNANDES, Ciane; MOURA, Rogério. "Des-Construindo Casas, Corpos e Cenas: Visitors Only, de Meg Stuart”. In: Revista Digital Art\&, ano II, n. 01, abril 2004.

FORSYTHE, William. Improvisation technologies: a tool for the analytical dance eye. CD-ROM. 1999.

FOUCAULT, Michel. História da sexualidade I: a vontade de saber. Rio de Janeiro: Edições Graal, 1988.

GIL, José. Movimento total: o corpo e a dança. São Paulo: Iluminuras, 2004.

HEUSLER, Dagmar-Lara (ed.) Körper und Raum, Wuppertal: Verlag Müller + Busmann, 1999.

HUXLEY, Michael \& WITTS, Noel. The Twentieth-Century Performance Reader. Londres: Routledge, 1997.

LABAN, Rudolf. Domínio do movimento. São Paulo: Summus, 1978.

LACERDA, Cláudio. Representações de Masculinidade na Dança e no Esporte: um Olhar sobre Nijinsky e Jeux. Recife: O Autor, 2010.

NUGENT, Ann. "Profile: William Forsythe". In Dance Theatre Journal, vol. 19, n 2, pp. 41-45. Londres: Laban, 2003.

Londres: Laban, 1998. . "Eyeing Forsythe". In Dance Theatre Journal, vol. 14, n 3, pp. 26-30.

PERRONE-MOISÉS, Leyla. “Aquele Que Desprendeu a Ponta da Cadeia”. In NASCIMENTO, Evando (org.). Jacques Derrida: Pensar a Desconstrução. São Paulo: Estação Liberdade, 2005.

PRESTON-DUNLOP, Valerie. Looking at dances: a choreological perspective on choreography. Londres: Verve, 1998.

RUBIDGE, Sarah. “Improvisation Technologies: A Tool for the Analytical Dance Eye' reviewed by Sarah Rubidge”. In Dance Theatre Journal. Vol.15, n 3, pp.46-47. Lon- 
dres: Laban, 1999.

SANCHEZ-COLBERG, Anna. "Altered States and Subliminal Spaces: Charting the Road Towards a Physical Theatre”. In Performance Research 1(2), pp. 40-56. Londres: Routledge, 1996.

SCHLICHER, Susanne. "O Corpo Conceitual". In Repertório Teatro \& Dança. Ano 4, no 5, 2001, pp. 30-36. Salvador: Universidade Federal da Bahia, Programa de Pós-Graduação em Artes Cênicas, 2001.

SCHROEDER, William R. "Philosophies of Dispersion”. In Continental Philosophy: a critical approach. Londres: Blackwell, 2005.

SERVOS, Norbert. Entrevista com Pina Bausch. In: HEUSLER, Dagmar-Lara (ed.) Körper und Raum, Wuppertal: Verlag Müller + Busmann, 1999.

. "William Forsythe”. In: HEUSLER, Dagmar-Lara (ed.) Körper und Raum, Wuppertal: Verlag Müller + Busmann, 1999

SIEGMUND, Gerald. "March into Death: William Forsythe Opens TAT with 'Endless House”. In Ballet Tanz. no 12, Dezembro 1999, pp. 46. Seelze: Friedrich Verlagsservice, 1999.

"A 360-Degree View of Ballet's Invisible Center: William Forsythe's New Ballet 'Woolf Phrase in Frankfurt”. In Ballet Tanz. no 11, Novembro 2001, pp. 20 23. Seelze: Friedrich Verlagsservice, 2001a.

. “Choreographic Thinking”. In Ballet Tanz Yearbook 2001. n 11, Novembro 2001, pp. 72-75. Seelze: Friedrich Verlagsservice, 2001b.

. "Frankfurt Blinds: 'Kammer/Kammer' by William Forsythe at the Bockenheimer Depot”. In Ballet Tanz. no 2, Fevereiro 2001, pp. 44-45. Seelze: Friedrich Verlagsservice, 2001c.

STUART, Meg \& PEETERS, Jeroen (ed.). Are We Here Yet? Bélgica: Les Presses du Réel, 2010. 